\title{
The effect of surface hydroxyl groups on the adsorption properties of nanocrystalline $\mathrm{TiO}_{2}$ films
}

\author{
Angela Šurca Vuk, ${ }^{1}$ Robi Ješe, ${ }^{1}$ Boris Orel, ${ }^{1, \dagger}$ and Goran Dražič ${ }^{2}$ \\ ${ }^{1}$ National Institute of Chemistry, Hajdrihova 19, 1000 Ljubljana, Slovenia \\ 2 Jožef Stefan Institute, Jamova 39, SI-1000 Ljubljana, Slovenia
}

\begin{abstract}
Nanocrystalline $\mathrm{TiO}_{2} / \mathrm{Brij}$ and $\mathrm{TiO}_{2} /$ Pluronic films were prepared with a view to their application in electrochromic and Grätzel cells and examination of their photocatalytic effect. The films were prepared from titanium (IV) isopropoxide with the addition of Brij 56 or Pluronic F127. Films were deposited by dip-coating, thermally treated at $500^{\circ} \mathrm{C}$ and analysed by XRD, TEM and IR analysis. XRD and TEM analyses revealed the presence of anatase nanoparticles embedded in the amorphous phase. The presence of the latter was also confirmed by a broad high-frequency shoulder of the Ti-O stretching mode at $436 \mathrm{~cm}^{-1}$ that was found for films prepared with both kinds of surfactants. Addition of surfactants decreased the size of the particles and increased the surface roughness, and consequently in IR spectra the surface hydroxyl Ti-OH modes appear between 3800 and $3600 \mathrm{~cm}^{-1}$. IR measurements also revealed that $\mathrm{TiO}_{2}$ films with surfactants have a higher photocatalytic effect which was tested for stearic acid by following the integral intensity of $\mathrm{C}-\mathrm{H}$ and $\mathrm{C}=\mathrm{O}$ IR bands.
\end{abstract}

\section{INTRODUCTION}

$\mathrm{TiO}_{2}$ is an ubiquitous material important for the development of various iono- and electro-optic devices such as dye-sensitised photoelectrochemical cells (DS PEC-Grätzel cells) [1, 2] or hybrid electrochromic devices [3-5]. Numerous publications deal with possible synthesis routes, the morphology of the films, nanocrystallinity, surface area and corresponding electrochemical properties, the latter aspect being investigated mainly for the anatase structure [1-3, 58]. Recently, $\mathrm{TiO}_{2}$ has also gained importance as a material that exhibits a self-cleaning effect due to its hydrophilic properties [7]. The large surface area of $\mathrm{TiO}_{2}$ and the presence of surface hydroxyl groups $[9,10]$ both influence its ability to adsorb photosensitive dyes such as derivatives of ruthenium bipyridyl complexes [6], redox chromophores (viologens, ...) [4] and water when superhydrophilicity [11] is concerned. Due to this reason, we prepared various $\mathrm{TiO}_{2}$ films with increased surface roughness and content of surface hydroxyl groups by sol-gel synthesis routes and the use of various surfactants (Brij 56, Pluronic F127). The reactive functional groups enabled the surfactants to bind to the tetrahedrally coordinated titanium alkoxy precursor by forming the more stable hexa-coordinated titanium, hence influencing the condensation reactions [12]. After thermal treatment at $500{ }^{\circ} \mathrm{C}$ organic components were removed from the films, with the films thus attaining pronounced surface morphology with a controlled size of titania grains and large surface area. This study was oriented towards the assessment of structural properties of $\mathrm{TiO}_{2}$ films synthesized with the

\footnotetext{
${ }^{\dagger}$ E-mail: boris.orel@ki.si
}

help of different surfactants by using IR, XRD and TEM measurements. The main aim was to show the correlations between their nanocrystalline structure and other properties such as photocatalytic effect, intercalation properties and related electrochromic effect. Infrared spectroscopic investigations also confirmed that ruthenium bipyridyl dyes are attached to the titania surface making $\mathrm{TiO}_{2}$ films efficient photoanodes for DS PEC.

\section{EXPERIMENTAL}

$\mathrm{TiO}_{2}$ sols were prepared from titanium (IV) isopropoxide and acetic acid in a $1: 1$ molar ratio in methoxyethanol. The appropriate surfactant, Brij 56 or Pluronic F127, was added while the sol was vigorously stirred. After additional stirring, the films were deposited by dip-coating on Si wafers polished both sides, followed by thermal treatment at $500{ }^{\circ} \mathrm{C}$. IR spectra of films deposited on the Si wafers were measured in the transmission mode using the FT-IR Perkin Elmer System 2000 or Bruker IFS 66/S spectrometer. Electrochemical measurements, in $0.1 \mathrm{M} \mathrm{LiOH}$, were performed using an Autolab PGSTAT30 potentiostat/galvanostat. The working electrode was $\mathrm{TiO}_{2} /$ Brij film on Si wafer, with an $\mathrm{Ag} / \mathrm{AgCl} / \mathrm{KCl}$ (sat.) and Pt wire acting as the reference and counter electrodes, respectively.

\section{RESULTS AND DISCUSSION}

The structure of $\mathrm{TiO}_{2}$ films, with and without surfactants, was characterised by various techniques (IR, XRD, TEM, AFM, SEM) that simultaneously confirmed the smaller particle size and higher amount of the amorphous phase when Brij and Pluronic were added 


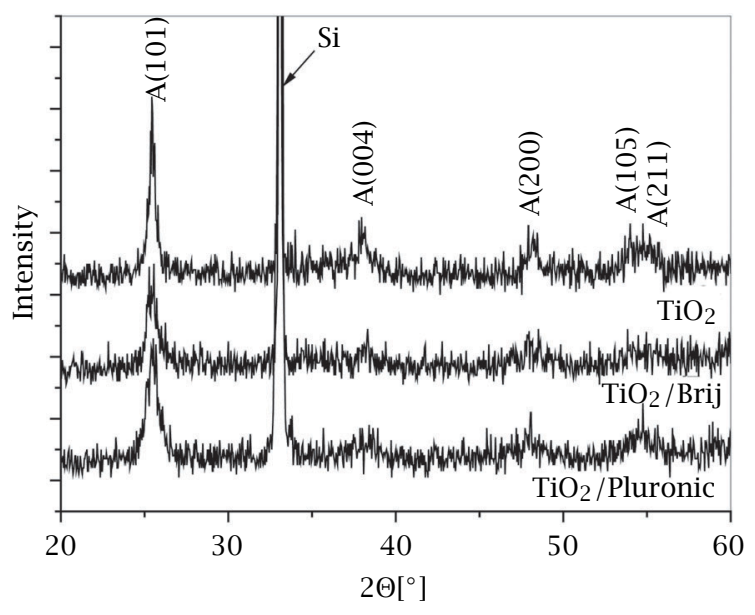

Figure 1. XRD spectra of $\mathrm{TiO}_{2}, \mathrm{TiO}_{2} /$ Brij and $\mathrm{TiO}_{2} /$ Pluronic films. Films were deposited by two successive dip-coating cycles, the first layer being thermally treated for $15 \mathrm{~min}$ and the second for $30 \mathrm{~min}$ at $500{ }^{\circ} \mathrm{C}$.

into the sols. XRD measurements of films that were prepared by two successive dipping cycles and heating at $500{ }^{\circ} \mathrm{C}$ (Figure 1) revealed the presence of the anatase phase in each film type, although the half-width of the diffraction peak $\mathrm{A}(101)$ increased in the order $\mathrm{TiO}_{2}>\mathrm{TiO}_{2} /$ Brij $>\mathrm{TiO}_{2} /$ Pluronic, with a corresponding decrease in the size of the nanograins from $23 \mathrm{~nm}$ in $\mathrm{TiO}_{2}$ to $12 \mathrm{~nm}$ in $\mathrm{TiO}_{2} /$ Pluronic. The presence of the rutile phase found in the XRD spectra of the powders (not shown here) is not evident from the XRD spectra of the films (Figure 1). Despite the fact that the XRD results did not show the presence of the rutile phase, it was possible to infer from the IR spectra the existence of a trace of the rutile phase on the surface of the $\mathrm{TiO}_{2}$ nanograins (see below).

The presence of the anatase particles that are embedded in the amorphous phase was also confirmed by SAED patterns obtained in combination with TEM micrographs (Figure 2A-C). TEM micrographs confirmed that the films prepared with surfactants have particles with smaller dimensions, which leads to increased surface roughness of these films (Figure 2A-C). A more detailed inspection of the $\mathrm{TiO}_{2} /$ Brij film revealed that the grains are composed of crystalline and amorphous parts, with the latter having an irregular texture (Figure 2D). No evidence about the formation of mesopores was obtained, even when films were severely etched. Higher surface roughness was also revealed by AFM measurements attaining $0.6-0.9 \mathrm{~nm}$ for pure $\mathrm{TiO}_{2}$ and increasing to $1.3 \mathrm{~nm}$ for films with Brij.

It is noteworthy that the presence of the amorphous phase can also be detected from transmission IR spectra of $\mathrm{TiO}_{2}$ films with surfactants. The films were deposited on silicon wafers that partly transmit IR radi- ation and the spectra were recorded immediately after thermal treatment at $500{ }^{\circ} \mathrm{C}$. The IR spectra were characterised by the sharp fundamental Ti-O stretching mode of anatase at $436 \mathrm{~cm}^{-1}$ [13] and a broad shoulder around $700 \mathrm{~cm}^{-1}$ (Figure 3A). This shoulder was of the lowest intensity for the pure $\mathrm{TiO}_{2}$ film (no surfactant) and increased in intensity simultaneously with an increase in the content of the amorphous phase $\left(\mathrm{TiO}_{2} / \mathrm{Brij}<\mathrm{TiO}_{2} /\right.$ Pluronic). The observed shoulder is ascribed to the presence of the amorphous phase, the feature not recorded so far.

The second important result obtained from IR spectroscopy is the appearance of surface hydroxyl modes between 3800 and $3600 \mathrm{~cm}^{-1}$ (Figure 3B) [9, 10]. This result is particularly fascinating because the surface hydroxyl modes usually became visible after thermal treatment at $300-400{ }^{\circ} \mathrm{C}$ in vacuum, but we observed them at ambient conditions. The surface hydroxyl modes are of very low intensity in pure $\mathrm{TiO}_{2}$ films. Their intensity, however, markedly increased when the surfactants Brij or Pluronic were added into the sols, and was also dependent on the heat-treatment temperature of the films. The surface hydroxyls appeared at 3693, 3674 and $3636 \mathrm{~cm}^{-1}$ and were attributed to -OH vibrations of the coordinatively unsaturated titanium ions located on the surface of $\mathrm{TiO}_{2}$ films with surfactants. Prior to giving a more defined assignment of the Ti-OH modes observed in the obtained spectra, it should be noted that the frequencies of surface hydroxyl modes strongly depend on the morphology of the films, preparation routes and type of $\mathrm{TiO}_{2}$ crystallites (anatase or rutile) that form during thermal treatment $[9,10]$. The reason that various surface hydroxyl modes exist lies in the fact that the oxygen atom of the $\mathrm{OH}$ group can coordinate to several neighbouring metal atoms. The surface hydroxyls could be free (isolated Ti-OH), hydrogen bonded one to another (vicinal) or bonded to water molecules chemically adsorbed on the $\mathrm{TiO}_{2}$ surface. The isolated hydroxyl group led to the highest frequency (wavenumber), while further formation of coordination bonds decreased its value. According to the literature data $[9,10]$, isolated $\mathrm{Ti}-\mathrm{OH}$ modes appear in the IR spectra of anatase in the spectral range between $3715-3728 \mathrm{~cm}^{-1}$, followed by vicinal and bridging Ti-OH modes. Additional bands may be noted when more then one crystal face is taken into account. The bands observed in our spectra at 3674 and $3636 \mathrm{~cm}^{-1}$ may be ascribed to vicinal and bridging Ti-OH modes of anatase. The band at $3690 \mathrm{~cm}^{-1}$, however, indicates that rutile may also be present at the surface of the $\mathrm{TiO}_{2}$ grains.

Information about the structure of $\mathrm{TiO}_{2} / \mathrm{Brij}$ and $\mathrm{TiO}_{2}$ /Pluronic films, gathered from this study and combined with the results of the IR spectra analysis (Figure 3), enabled investigation of the films while employed in their possible applications. For example, electrochromic effect (hybrid electrochromic devices), 


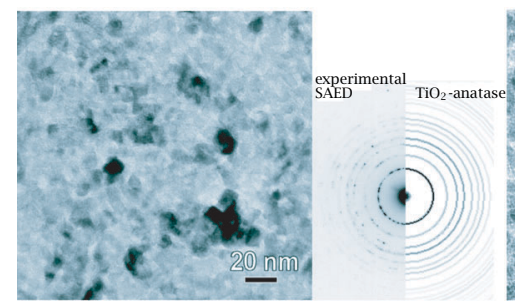

A

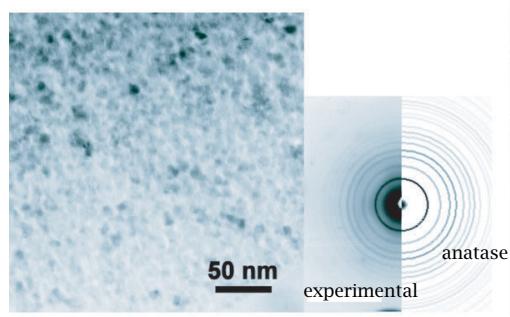

C

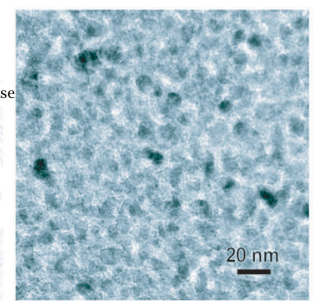

B

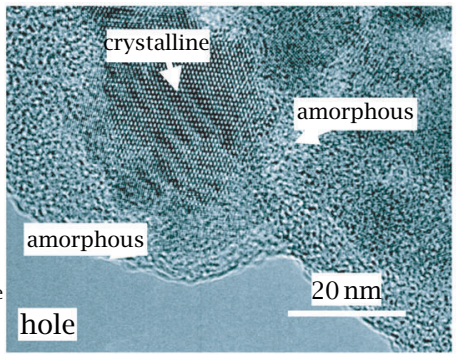

D

Figure 2. TEM micrographs with SAED patterns of: $(A) \mathrm{TiO}_{2},(B) \mathrm{TiO}_{2} /$ Brij and (C) $\mathrm{TiO}_{2} /$ Pluronic films. Films were deposited by two successive dip-coating cycles, the first layer being thermally treated for $15 \mathrm{~min}$ and the second for $30 \mathrm{~min}$ at $500{ }^{\circ} \mathrm{C}$. (D) TEM micrograph of a $\mathrm{TiO}_{2} /$ Brij film with indicated crystalline and amorphous regions.
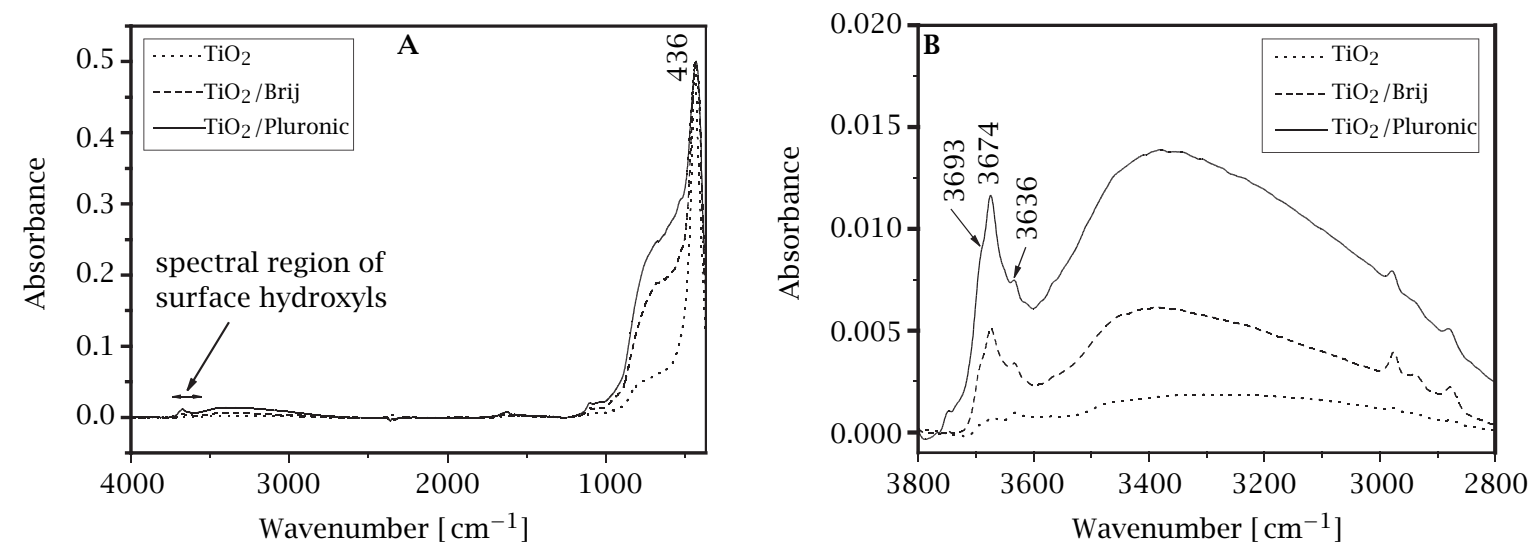

Figure 3. IR spectra of $\mathrm{TiO}_{2}, \mathrm{TiO}_{2} /$ Brij and $\mathrm{TiO}_{2} / \mathrm{Pluronic}$ films: (A) $4000-400 \mathrm{~cm}^{-1}$ and (B) $4000-2500 \mathrm{~cm}^{-1}$. Films were deposited by two successive dip-coating cycles, the first layer being thermally treated for $15 \mathrm{~min}$ and the second for $30 \mathrm{~min}$ at $500{ }^{\circ} \mathrm{C}$.

attachment of ruthenium bipyridyl dye (DS PEC cells) and photocatalytic effect. The electrochromic effect of $\mathrm{TiO}_{2} /$ Brij films was tested in $0.1 \mathrm{M} \mathrm{LiOH}$ electrolyte [5]. The film was deposited on Si wafer and initially simply soaked in the electrolyte, while subsequently it was charged to -19 and $-77 \mathrm{mC} \mathrm{cm}^{-2}$ and discharged to $112 \mathrm{mC} \mathrm{cm}^{-2}$. Following soaking, charging and discharging, the film was removed from the electrochemical cell, cleaned with distilled water, dried with $\mathrm{N}_{2}$ flux and measured in the sample compartment of the IR spectrometer (Figure 4). The IR spectra did not reveal any changes of the Ti-O stretching mode at $436 \mathrm{~cm}^{-1}$, which was substantiated by the disappearance of the blue colour typical of $\mathrm{TiO}_{2}$ in the reduced state. The manipulation of the $\mathrm{TiO}_{2} /$ Brij film outside the electrolyte led to discharging (Figure 4A). On the other hand, marked changes in the spectral range of the surface hydroxyl modes were noted (Figure 4B). For example, after soaking, the band at $3693 \mathrm{~cm}^{-1}$ that was ascribed to the vicinal Ti-OH modes of the rutile phase increased in intensity. A further increase in intensity was noted after charging to $-77 \mathrm{mC} \mathrm{cm}^{-2}$, while discharging led to a spectrum similar to that of the soaked film. The observed changes in the $3693 \mathrm{~cm}^{-1}$ band were repeatable for $\mathrm{TiO}_{2} /$ Brij films, but when one film was soaked overnight in electrolyte the surface hydroxyl bands became blurred by the increased absorption of water molecules. However, the explanation for the increased 

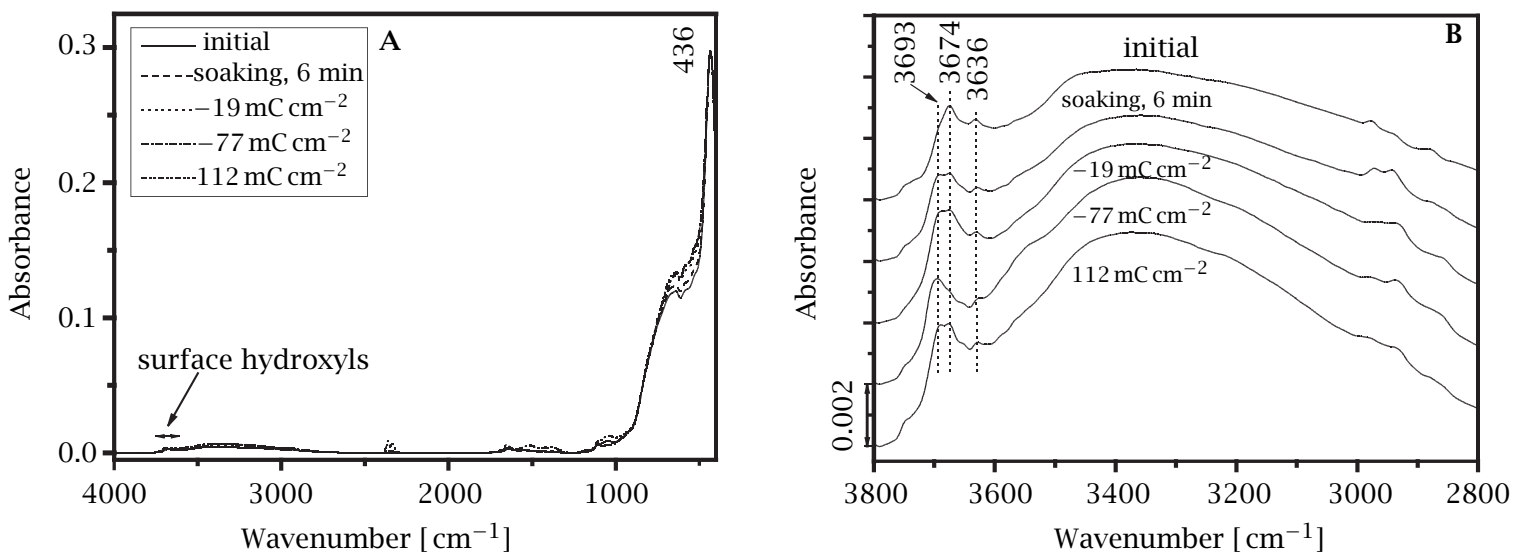

Figure 4. Ex-situ IR spectroelectrochemical measurements of a $\mathrm{TiO}_{2}$ / Brij film deposited by two successive dip-coating cycles on Si wafer and thermally treated at $500{ }^{\circ} \mathrm{C}$. The IR spectra were measured after soaking, charging to -19 and $-77 \mathrm{mC} \mathrm{cm}^{-2}$ and discharging to $112 \mathrm{mC} \mathrm{cm}^{-2}$ : (A) $4000-400 \mathrm{~cm}^{-1}$ and (B) $3800-3500 \mathrm{~cm}^{-1}$.
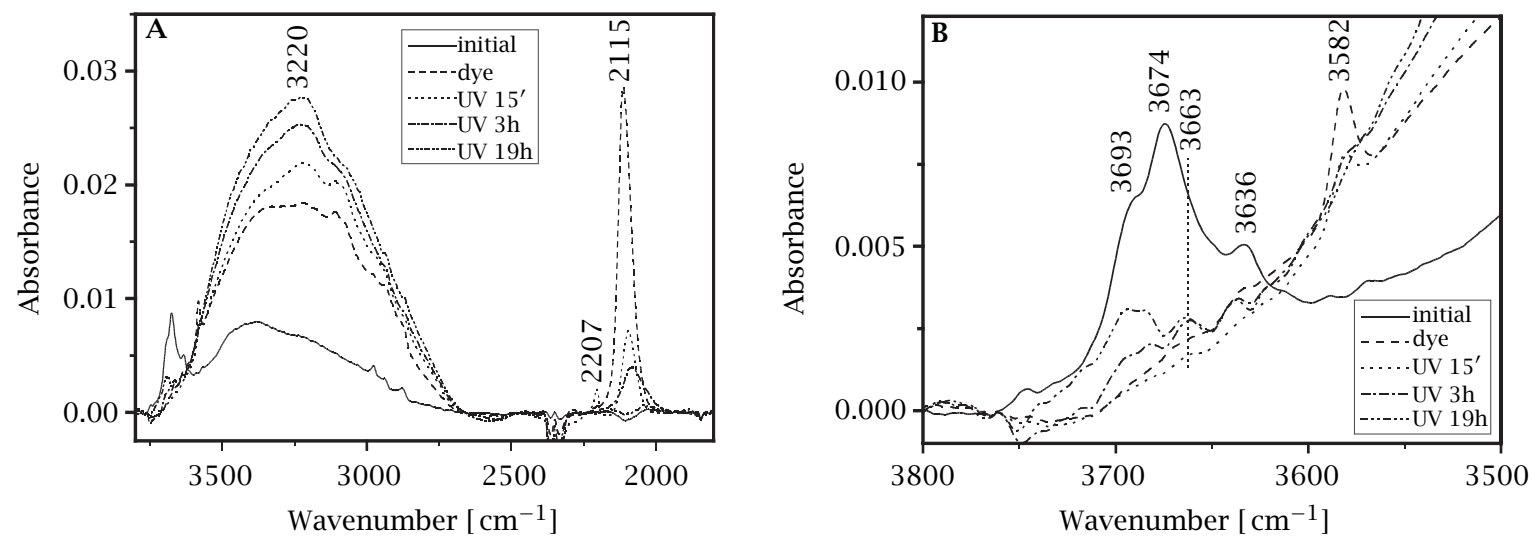

Figure 5. IR spectra of a $\mathrm{TiO}_{2} /$ Pluronic film deposited by two successive dip-coating cycles on $\mathrm{Si}$ wafer and thermally treated at $500{ }^{\circ} \mathrm{C}$. The IR spectra were measured after the film was soaked into ruthenium bipyridyl dye and then exposed to UV radiation: (A) $3800-1800 \mathrm{~cm}^{-1}$ and (B) $3800-3500 \mathrm{~cm}^{-1}$.

intensity of the $3693 \mathrm{~cm}^{-1}$ band during charging is not yet completely clear, but the process may be similar to the hydroxylation of the coordinatively unsaturated $\mathrm{Ti}^{3+}$ sites that after coordination attain $\mathrm{Ti}^{4+}\left(1^{\mathrm{OH}}-1-0-\right.$ 0-0) state.

The $\mathrm{TiO}_{2}$ films with high surface area are compulsory for DS PEC $[1,2,6]$. From the point of view of the efficiency of the $\mathrm{TiO}_{2}$ films it is interesting to know what the bonding sites of the ruthenium-dye to $\mathrm{TiO}_{2}$ surface [6] are. This was investigated on a $\mathrm{TiO}_{2} /$ Pluronic film by measuring IR spectra of the initial film, film covered with the dye, and then film with attached dye exposed to UV radiation (15 min, $3 \mathrm{~h}$ and $19 \mathrm{~h}$ ), (Figure 5). Analysis of the IR spectra of non-irradiated films revealed two bands belonging to the SCN groups of the dye at 2115 and $3582 \mathrm{~cm}^{-1}$ [14], while the spectra of the irradiated films exhibited a significant decrease of the band intensities (15 min) and their complete extinction after
$19 \mathrm{~h}$ of exposure to UV radiation. Degradation of the dye was accompanied by changes in the Ti-OH modes (Figure 5B). The fastest hydroxylation was noticed for the vicinal Ti-OH hydroxyl modes $\left(3693 \mathrm{~cm}^{-1}\right)$, on which the dye was not strongly attached [6]. These results directly support the proposed attachment of the ruthenium dye on the anatase surface [6].

The photocatalytic properties of the $\mathrm{TiO}_{2}$ films and powders are important for many areas of applications [7]. Photocatalytic effect was tested for $\mathrm{TiO}_{2}$ and $\mathrm{TiO}_{2} /$ Brij film by measuring the loss of intensity of the IR bands of stearic acid $\left(\mathrm{CH}_{3}\left(\mathrm{CH}_{2}\right)_{16} \mathrm{COOH}\right)$ with the radiation dose (Figure 6). Stearic acid was deposited on both kinds of $\mathrm{TiO}_{2}$ films by dipping them into hot $0.4 \mathrm{M}$ solution of stearic acid in methanol. IR spectra of the film were measured after illumination with UV for 0 , 1,2 and $3 \mathrm{~h}$ (Figure 6A, B). The degradation of stearic acid was followed by measuring the integral intensity 

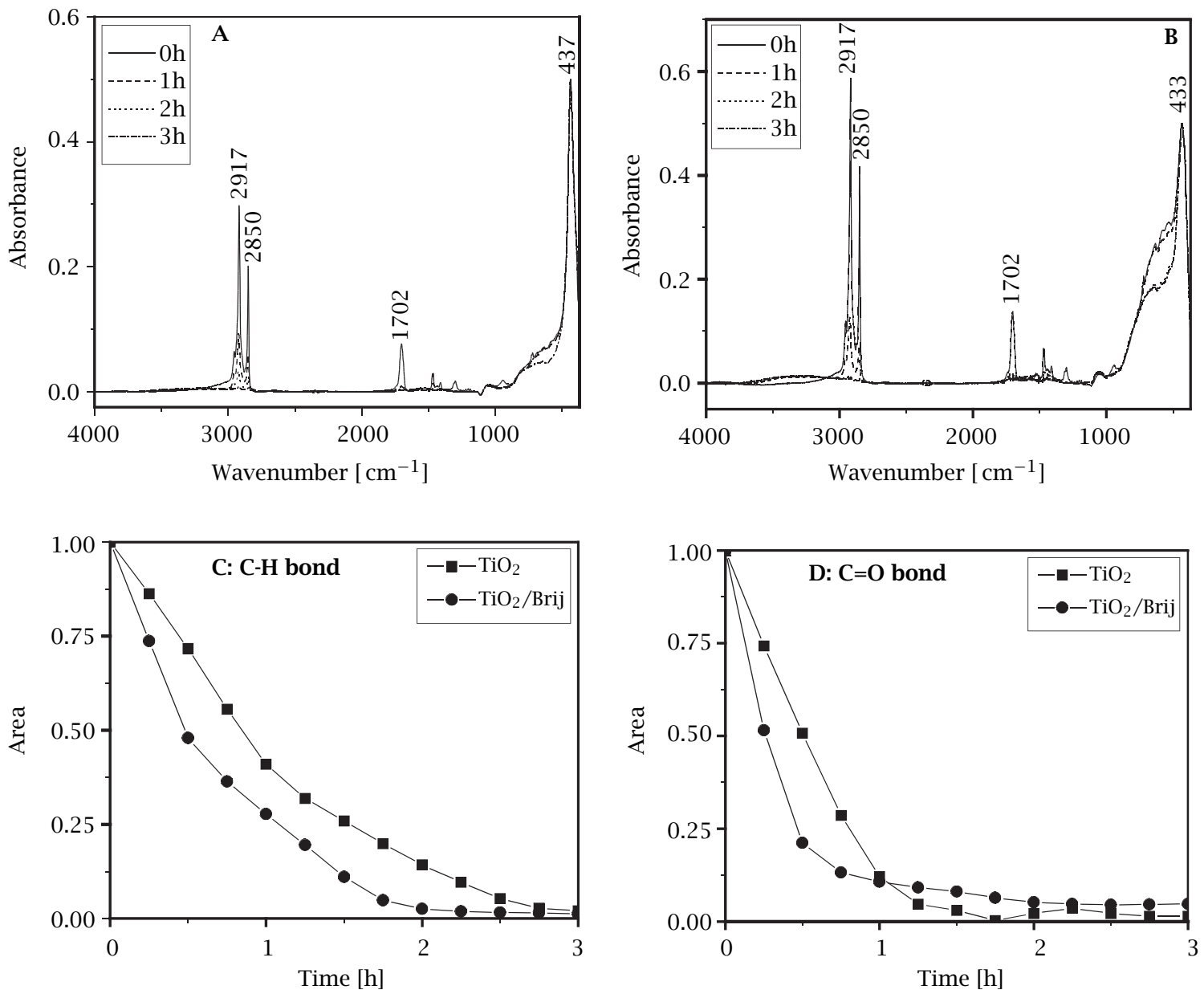

Figure 6. IR measurements of the photocatalysis of stearic acid on a: (A) $\mathrm{TiO}_{2}$ and (B) $\mathrm{TiO}_{2} / \mathrm{Brij}_{\text {film. }}$ Changes in area of the IR bands that occur during 3 hours are shown for: (C) C-H bonds between 2800 and $3000 \mathrm{~cm}^{-1}$ and $(D) \mathrm{C}=\mathrm{O}$ bond.

of the vibrational bands of the acid ( $\mathrm{C}-\mathrm{H}$ bands between 3000 and $2800 \mathrm{~cm}^{-1}$ and $\mathrm{C}=\mathrm{O}$ band at $\left.1702 \mathrm{~cm}^{-1}[14]\right)$ (Figure 6C, D). It was found that the increased surface roughness exhibited by the $\mathrm{TiO}_{2} /$ Brij film compared to pure $\mathrm{TiO}_{2}$ led to faster decrease of the $\mathrm{C}-\mathrm{H}$ and $\mathrm{C}=\mathrm{O}$ bonds and therefore faster degradation of the stearic acid. $\mathrm{TiO}_{2}$ /Brij films were found to be more photocatalytically effective.

\section{CONCLUSIONS}

In this work we used IR spectroscopy as a powerful tool for the investigation of nanocrystalline $\mathrm{TiO}_{2}$ films from the point of view of their electrochromic effect, photocatalytic effect and their use as photoanodes in Grätzel cells. The nanocrystallinity and surface roughness of the $\mathrm{TiO}_{2}$ films was increased by addition of the surfactants Brij 56 and Pluronic F127. Consequently, the increased surface led to a higher concentration of surface hydroxyls (Ti-OH) in $\mathrm{TiO}_{2}$ films with surfactants compared to pure $\mathrm{TiO}_{2}$ films, and to the appearance of Ti$\mathrm{OH}$ modes in IR spectra at 3693, 3674 and $3636 \mathrm{~cm}^{-1}$.
The former IR band belong to vicinal Ti-OH of the rutile phase, while the latter two were assigned to $\mathrm{Ti}-\mathrm{OH}$ of the anatase phase (vicinal and H-bonded to water molecules). Results revealed that electrochemical treatment in $0.1 \mathrm{M} \mathrm{LiOH}$ influenced the $3693 \mathrm{~cm}^{-1}$ band to the greatest extent, and the changes in its intensity were reversible. With regard to the use of $\mathrm{TiO}_{2}$ films in DS PEC we investigated the attachment of the rutheniumdye to the $\mathrm{TiO}_{2}$ /Pluronic film, revealing dehydroxylation after attachment of the dye, but formation of the $3693 \mathrm{~cm}^{-1}$ band after exposure to UV radiation. Our $\mathrm{TiO}_{2}$ films with surfactants were also characterised by an increased photocatalytic effect.

\section{ACKNOWLEDGMENTS}

This work was supported by the Ministry of Higher Education, Science and Technology of Slovenia and was performed in the frame of the project J1-5010 and programme P1-0030. Robi Ješe thanks the Ministry for his Ph.D. grant. 


\section{REFERENCES}

[1] B. O’Regan and M. Grätzel, Nature (London) 353 (1991), 737.

[2] U. Lavrenčič Štangar, B. Orel, A. Šurca Vuk, G. Sagon, Ph. Colomban, E. Stathatos, and P. Lianos, J. Electrochem. Soc. 149 (2002), E413.

[3] C. G. Granqvist, Handbook of Inorganic Electrochromic Materials, Elsevier Science, Amsterdam, 1995, Ch. 15.

[4] R. Cinnsealach, G. Boschloo, S. Nagaraja Rao, and D. Fitzmaurice, Solar Energy Mater. \& Sol. Cells 55 (1998), 215.

[5] A. Šurca Vuk, R. Ješe, M. Gaberšček, B. Orel, and G. Dražič, submitted to Solar Energy Mater. \& Sol. Cells.

[6] K. S. Finnie, J. R. Bartlett, and J. L. Woolfrey, Langmuir 14 (1998), 2744.

[7] A. Fujishima, K. Hashimoto, and T. Watanabe, $\mathrm{TiO}_{2}$, Photocatalysis, Fundamentals and Applications, BKC, Inc., Tokyo, 1999.
[8] L. Kavan, J. Rathouský, M. Grätzel, V. Shklover, and A. Zukal, J. Phys. Chem. B 104 (2000), 12012.

[9] A. Davydov, Molecular Spectroscopy of Ocide Catalyst Surfaces, John Wiley, New York, 2003.

[10] K. I. Hadjiivanov and D. G. Klissurski, Chem. Soc. Rev. (1996), 61.

[11] R. Wang, N. Sakai, A. Fujishima, T. Watanabe, and K. Hashimoto, J. Phys. Chem. B 103 (1999), 2188.

[12] N. Huesing, B. Launay, G. Kickelbick, S. Gross, L. Armelao, G. Bottaro, M. P. Feth, H. Bertagnolli, and G. Kothleitner, Appl. Catalysis A 254 (2003), 297.

[13] R. J. Gonzalez and R. Zallen, Phys. Rev. B 55 (1997), 7014.

[14] K. Nakamoto, Infrared and Raman Spectra of Inorganic and Coordination Compaunds, 4th ed., John Wiley, New York, 1986. 


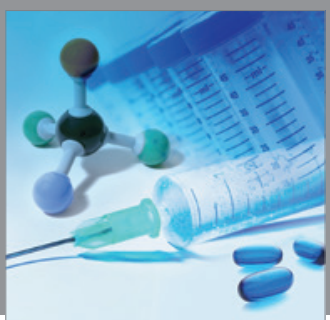

International Journal of

Medicinal Chemistry

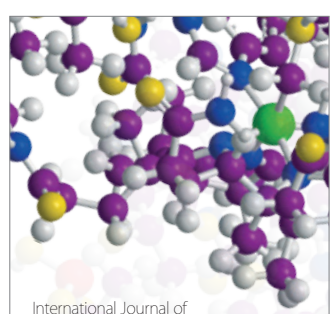

Carbohydrate Chemistry

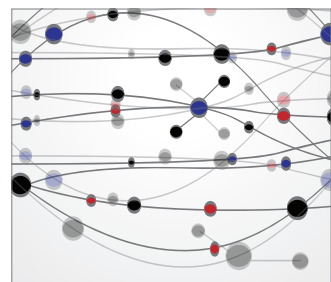

The Scientific World Journal
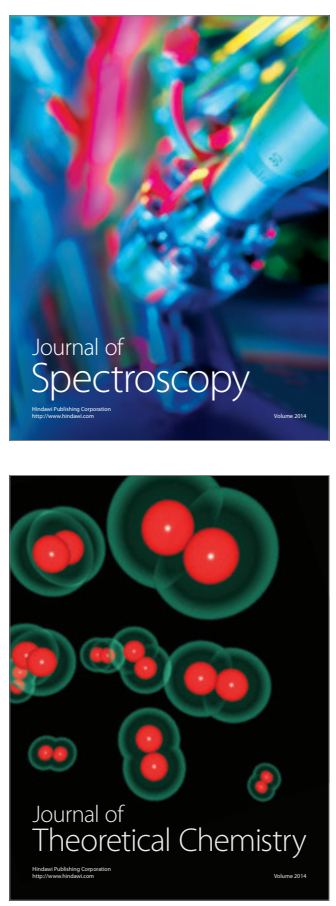
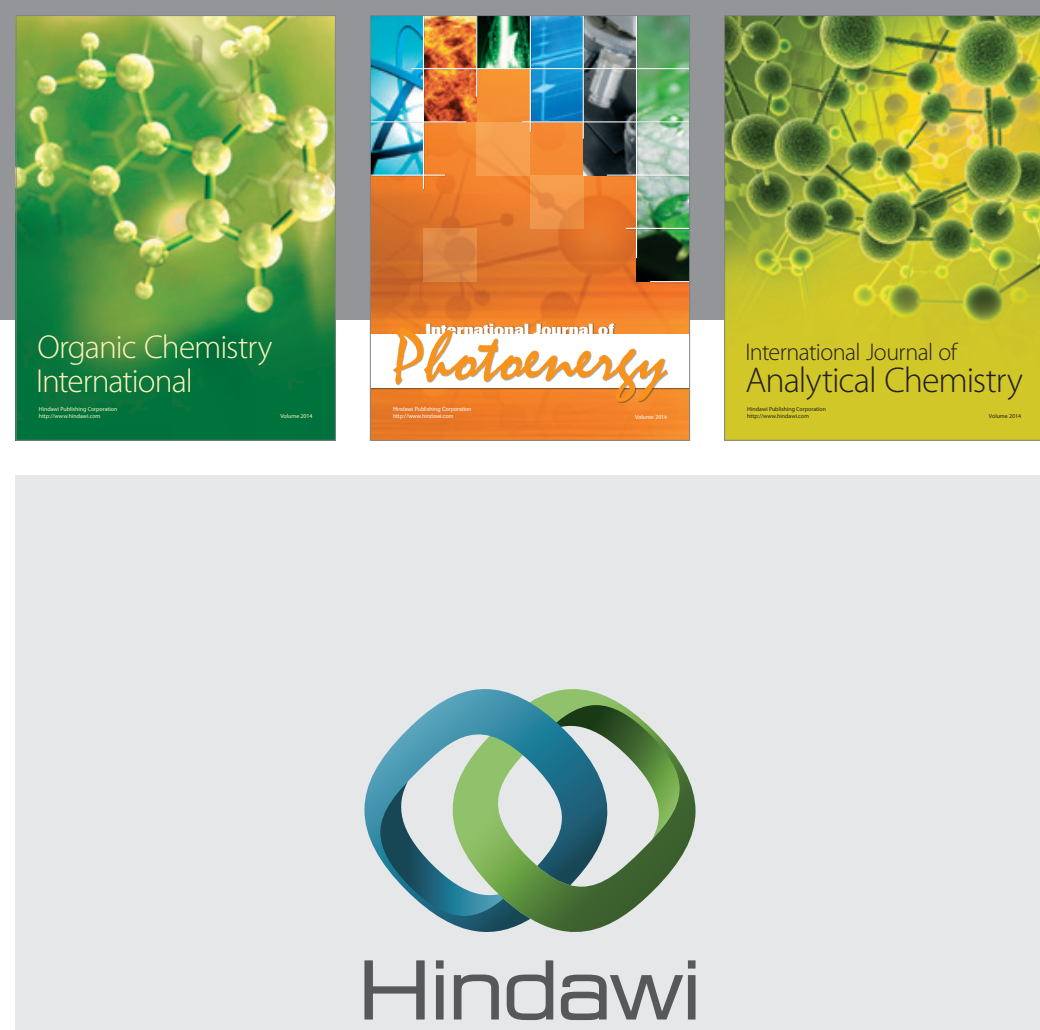

Submit your manuscripts at

http://www.hindawi.com
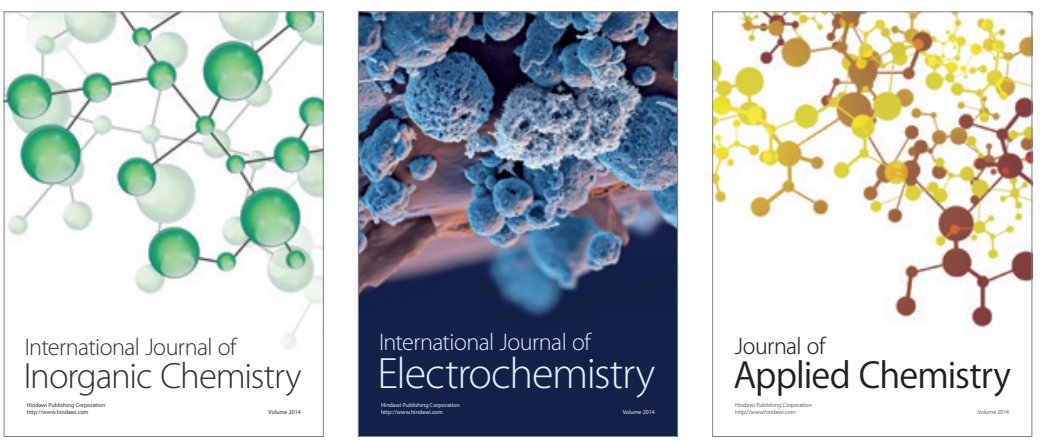

Journal of

Applied Chemistry
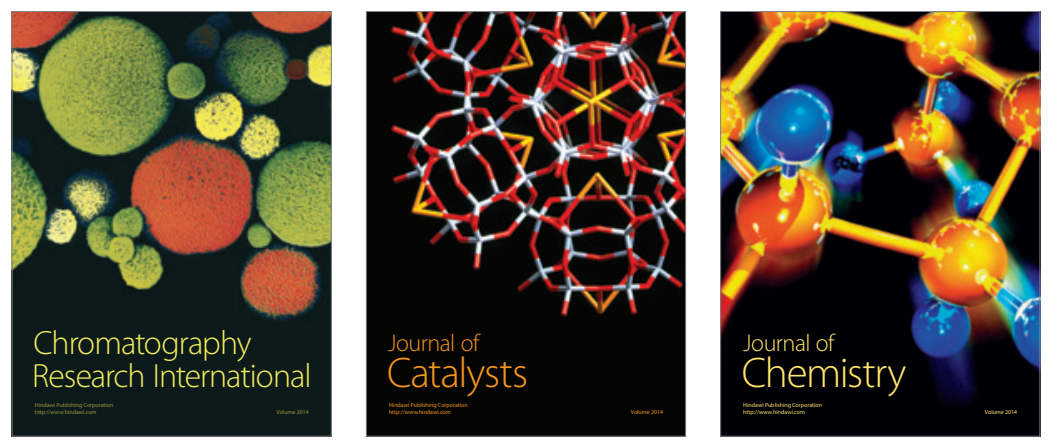
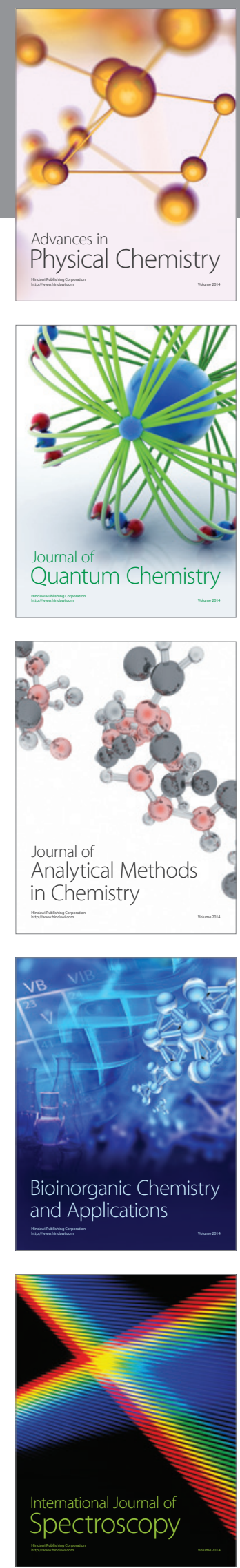